
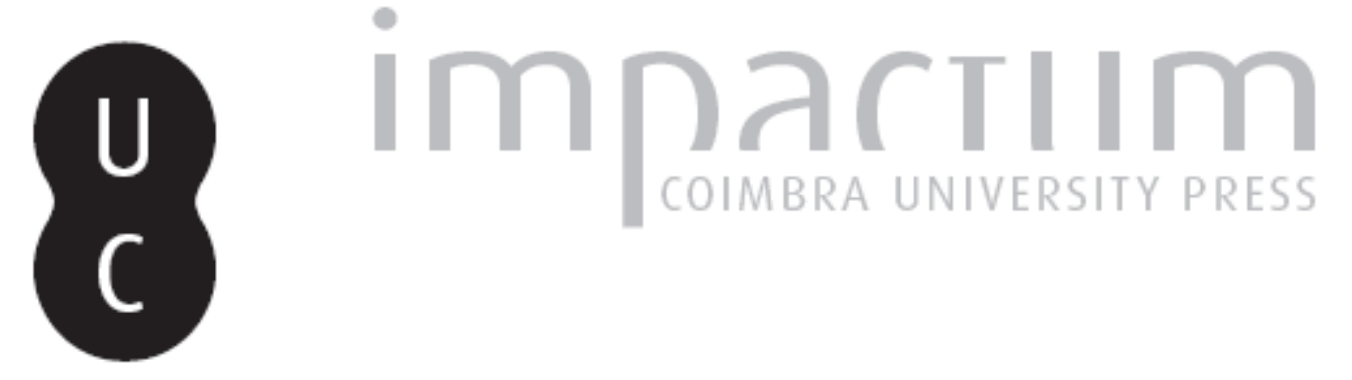

\title{
Percepção e desejo: leituras de R. Barbaras
}

\section{Autor(es): Umbelino, Luís António}
Publicado por: Faculdade de Letras da Universidade de Coimbra, Instituto de Estudos Filosóficos

URL

persistente:

URI:http://hdl.handle.net/10316.2/33371

DOI:

DOI:http://dx.doi.org/10.14195/0872-0851_35_4

Accessed : $\quad$ 26-Apr-2023 15:25:24

A navegação consulta e descarregamento dos títulos inseridos nas Bibliotecas Digitais UC Digitalis, UC Pombalina e UC Impactum, pressupõem a aceitação plena e sem reservas dos Termos e Condições de Uso destas Bibliotecas Digitais, disponíveis em https://digitalis.uc.pt/pt-pt/termos.

Conforme exposto nos referidos Termos e Condições de Uso, o descarregamento de títulos de acesso restrito requer uma licença válida de autorização devendo o utilizador aceder ao(s) documento(s) a partir de um endereço de IP da instituição detentora da supramencionada licença.

Ao utilizador é apenas permitido o descarregamento para uso pessoal, pelo que o emprego do(s) título(s) descarregado(s) para outro fim, designadamente comercial, carece de autorização do respetivo autor ou editor da obra.

Na medida em que todas as obras da UC Digitalis se encontram protegidas pelo Código do Direito de Autor e Direitos Conexos e demais legislação aplicável, toda a cópia, parcial ou total, deste documento, nos casos em que é legalmente admitida, deverá conter ou fazer-se acompanhar por este aviso.








vol.18|n. $.35 \mid 2009$

João Maria André

Mário Santiago de Carvalho

Filipa Medeiros

Edmundo Balsemão Pires

Luís António Umbelino

Luís M. Augusto

Lucas Angioni 


\title{
PERCEPÇÃO E DESEJO. LEITURAS DE R. BARBARAS
}

\author{
LUÍS ANTÓNIO UMBELINO
}

(Departamento de "Filosofia, Comunicação e Informação" - F.L.U.C. - Universidade de Coimbra)

\begin{abstract}
This paper aims to meditate on the originality of Renaud Barbaras phenomenology of perception, as presented in his book Le désir et la distance. Introduction à une phénoménologie de la perception. First of all we will focus our attention on the shadow of major philosophical projects dedicated to the theme namely that of Merleau-Ponty; then we will try to find the main thesis developed by Barbaras, while trying to think what remains to be thought on perception: the connection between perception and vital movement as desire.
\end{abstract}

Key-words: Perception; Phenomenology; Body, Movement; Life; Desire.

1.

O problema da percepção é, porventura, aquele que nos oferece a ocasião mais privilegiada de interrogar a especificidade da nossa inalienável presença no mundo. Na percepção joga-se, efectivamente, toda a malha de questões radicais e fundadoras que se prendem com a singularidade da nossa abertura, disposição, ligação e pertença a qualquer coisa que há. Neste sentido, deve entender-se em questão, por um lado, um modo de acesso à realidade tal como ela é nela própria ${ }^{1}$; perceber é sempre perceber as próprias coisas e não um duplo ou imagem, por isso, concomitantemente, ao percepcionar estamos convictos de que percebemos uma realidade que sustenta o olhar. Por outro lado, no entanto, "a percepção é sensível, isto é,

${ }^{1}$ BARBARAS, R., La perception. Essai sur le sensible, Hatier, Paris, 1994. Reeditado na Vrin, Paris, 2009. É esta última edição que utilizamos, p. 8. Citado La perception. 
minha" 2 e, neste sentido, se me abre à realidade concreta das coisas é por ser também a própria experiência que eu faço dessa realidade.

Ao nível concreto-originário ${ }^{3}$ da experiência antepredicativa, as dimensões referidas parecem ser reconhecidas, em exercício, como duas faces de uma mesma aptidão ou de um mesmo eu posso. A esse nível, tudo se passa como se "soubéssemos" que a percepção se faz ali no mundo e em mim (R. Barbaras), ali no mundo e, simultaneamente, aqui no coração da visão (Merleau-Ponty). E, no entanto, as doutrinas tradicionais sobre a percepção quase nunca foram capazes de pensar essa origem relacional, enredando a percepção em equívocos que, de um modo ou de outro, obnubilaram a sua realidade. Esta é, pelo menos, a perspectiva de Merleau-Ponty que, em consonância com tal diagnóstico, logo em 1933, ao esboçar o seu plano de investigação sobre a percepção ${ }^{4}$ o cunhou com uma inequívoca faceta crítica. Ante todo um conjunto de desenvolvimentos teóricos que ocorreram no campo filosófico, da psicologia, da biologia e mesmo da física, viu o filósofo a urgência em remeditar a noção de percepção a partir de novas bases, que não as oferecidas pelo horizonte datado e, em muitos aspectos, equívoco das doutrinas clássicas. A crítica de Merleau-Ponty incidirá sobre o que o filósofo denomina de "pensamento objectivo" e que considera nutrir tanto as doutrinas plasmadas pelo empirismo como pelo intelectualismo. Nenhuma dessas doutrinas, segundo o fenomenólogo francês, fez justiça à questão da percepção, pois seja sob que forma for que tal pensamento objectivo trate a questão, sempre a percepção é analisada a partir do seu desmembramento em componentes aparentemente antagónicas; estas, por seu turno, parecem ganhar mais ou menos importância ao ritmo do modo como cada um dos partidários de cada uma das doutrinas os vai acentuando. Ora, é curioso que, em última análise, cada uma dessas dimensões, em cada uma dessas doutrinas, pareça exigir a componente da doutrina contrária componente que acaba por não ser ponderada por força do antagonismo conceptual em que se encerra.

Merleau-Ponty compreendeu bem os limites que se desenham em tal "estrabismo". O empirismo - que para o Merleau-Ponty de La structure du comportement é ilustrado pelo behaviorismo e, em particular, pela reflexologia pavloviana ${ }^{5}$-, centrado quase exclusivamente sobre os

\section{${ }^{2}$ La perception, p. 8.}

${ }^{3}$ DIAS, Isabel, Matos, Uma Ontologia do Sensível. A Aventura Filosófica de Merleau-Ponty, Centro de Filosofia da Universidade de Lisboa, Lisboa, 1999, p. 37.

${ }^{4} \mathrm{Cf}$. MERLEAU-PONTY, M., Le primat de la perception et ses conséquences philosophiques, Verdier, 1996, p. 11.

5 Cf. MERLEAU-PONTY, M., La structure du comportement, (1942), P.U.F., Quadrige, Paris, 1990, cap. I, pp. 5 e ss. 
estímulos sensíveis vindos do exterior e apressado em sublinhar o facto de serem eles que nos colocam em relação com uma realidade existente, esquece a necessidade de dar conta da dimensão ou condição subjectiva para a qual há estímulos com um sentido ou significado determinado; simetricamente, o intelectualismo - que em Phénoménologie de la perception $^{6}$ surge associado a autores como Descartes ou Kant e mesmo, em determinado sentido, a Husserl - dissocia a experiência perceptiva originária: ao centrar-se sobre o papel do "sujeito" tende a reduzir o perceber ao acto de conceber do entendimento, assim falhando a compreensão das condições que permitem a dimensão inelutável de relação às próprias coisas. Ora, se assumíssemos tais doutrinas, segundo Merleau-Ponty, tudo passaria a existir como coisa ou como consciência, sem "meio", sem movimento, sem mistura. Ou seja, de um modo ou de outro, tais soluções "abstractas"8 conduzir-nos-iam sempre a perder o contacto com a experiência perceptiva.

A razão pela qual as conceptualizações clássicas não foram capazes de dar conta de tal unidade na diferença (e de diferentes), de tal dualidade (não dualismo) relacional que corresponde à experiência perceptiva, prende-se com opções específicas de pensamento que se unem num mesmo pressuposto de base, aceite de forma cega. As diversas formas que assume o pensamento objectivo convergem num pressuposto de adequação e na presunção de um "em si" inabalável e absoluto: "o mundo constituído para o empirismo; o sujeito constituinte para o intelectualismo." " Tal paradigma da plenitude, do estático e da adequação, consubstancia-se num quadro teórico conduzido por um triplo eixo equívoco e acrítico: o eixo de uma concepção determinada de experiência, de ser e do próprio acto filosófico. A experiência é tida como não podendo ter sentido senão como posse em transparência, como preenchimento integral do olhar pelo objecto, por seu lado entendido como idêntico, estável e plenamente presente. $\mathrm{O}$ momento da experiência deve confundir-se com essa "presença plena", ou seja, deve excluir "o recuo, a indeterminação, a fluidez dos contornos, a insatisfação" 10 , em nome da

${ }^{6}$ Cf. MERLEAU-PONTY, M., Phénoménologie de la perception, Gallimard, Paris, 1945, p. 73.

7 MERLEAU-PONTY, M., Phénoménologie..., o. c., p. 47

${ }^{8}$ La perception, p. 38

${ }^{9}$ DIAS, Isabel Matos, Uma Ontologia do Sensível, o. c., p. 39.

${ }^{10}$ La perception, p. 38-39. Empirismo e intelectualismo reconhecem apenas dois modos fixos de ser: mundo e consciência, "em si" e "para si", reduzindo respectivamente a "objecto" toda a coisa percebida e a "estado subjectivo" toda a actividade perceptiva. Neste sentido, confluem inevitavelmente na mesma abstracção de um objecto "em si" idêntico e estável, ou seja, só conseguem conceber a abertura perceptiva ao mundo como "presença plena de uma "coisa", ou subsunção pelo espírito das qualidades sensíveis. 
exigência de uma adequação integral. Subjacente a tal concepção de experiência encontra-se a opção por uma "ontologia do objecto": se, de um modo ou de outro, a realidade não pode chegar à presença senão como plena e adequada, se ela coincide integralmente com o que a torna presente, se a presença da "coisa percebida" é plenitude do que há a perceber, então, o percebido caracteriza-se como "objecto" plenamente disponível. O mesmo é dizer que se trata de propalar a hipótese - injustificada - da possibilidade de exaurir todo e qualquer tipo de negatividade no âmbito da percepção. E tal opção é, com toda a evidência, sustentada por uma inequívoca "submissão não questionada e frequentemente inconsciente ao princípio de razão suficiente" 11 , que se orienta pelo ponto de vista da questão - falsa (Bergson) e prejudicial (R. Barbaras) - "por que razão existe o ser e não o nada?" Através das lentes de tal princípio, a realidade é pressuposta como plenamente determinável, ou seja, como algo que resiste a um nada prévio e que o vem preencher como seu contrário vencedor. O ser é plenitude, logo, estrita e completa positividade; dito de outro modo, só é o que é porque nega e nos põe a salvo do fundo de nada que a presença integral consegue vencer. Nesta perspectiva, o real é pura determinação e só por isso é; nenhuma indeterminação ou negatividade deve, pois, permanecer no ser sob o risco deste deixar de ser e regressar ao nada ${ }^{12}$. A este claustrofóbico autoritarismo da presença plena e da transparência absoluta corresponde, finalmente, uma certa atitude filosófica a que poderíamos, com Merleau-Ponty, apelidar de ponto de vista de sobrevoo, de ausência da pertença ${ }^{13}$, de ignorância da vida. De facto, ao serviço de tal concepção empobrecedora de experiência e de tal princípio sustentador da adequação só poderia estar o ponto de vista ubíquo de um sujeito que manipula mas se recusa a habitar a realidade, de um sujeito que julga o seu poder de domínio pela capacidade de afastamento e de totalização racional capaz de retirar o ser da noite do nada prévio.

${ }^{11} \mathrm{Cf}$. BARBARAS, R., Le désir et la distance. Introduction à une phénoménologie de la perception, Vrin, Paris, 1999. 61 e ss. Citado Le désir et la distance.

${ }^{12}$ Le désir et la distance, p. 67: "En effet, dès lors que l'Être est ce qui est mis en balance avec le néant, il ne peut être que dans la mesure où il possède pour ainsi dire de quoi lui résister, où il est aussi pleinement que le néant qui le menace n'est pas. Il est donc absolument déterminé car le moindre indétermination signifierait son absorption par le non être, car il ne serait pas du tout s'il n'était pas pleinement : l'Être est de part en part ce qu'il est, pure présentation de lui-même."

${ }^{13}$ La perception, p. 41. 
Mas se se passa pela ideia de nada para chegar ao Ser, não se dará o caso como viu Bergson, de se encontrar apenas uma essência lógica ou matemática, por conseguinte intemporal"14, estática e empobrecidamente conformada à visão de um sujeito sobrevoante e estrábico? Ou seja, como notou Merleau-Ponty, não será que assim se ficará acriticamente preso à bizarra alternativa "de não perceber nada no sujeito, ou de não perceber nada no objecto"? Não será que o que falta pensar é, justamente, em que medida o mundo, ao ser percebido, está todo no meu interior mas apenas porque eu estou todo fora de $\mathrm{mim}^{15}$, a que ponto eu percebo o mundo porque a minha exterioridade se encontra totalmente no interior desse mundo?

Presença integral de um objecto determinado, experiência como adequação plena, submissão ao princípio de razão suficiente, ponto de vista de sobrevoo, enquadram uma concepção do real que desacredita a abertura, o movimento, a pertença conivente, a esquiva. Falha-se, deste modo, essa "deflagração do Ser" que inspira em vazio a experiência perceptiva e que o pintor ensina aos demais homens ser necessário "tomar à letra". Cézanne, como compreendeu Merleau-Ponty, havia pressentido essa deflagração quando dizia que vemos a profundidade, o aveludado, a moleza, a dureza dos objectos, e mesmo o seu odor ${ }^{16}$. Assim dava notícia dessa textura de toda a "coesão", desse "fundo imememorial do visível"17, que invade o corpo e motiva a experiência muda a chegar à sua própria expressão. $\mathrm{O}$ pintor sabe bem que o acesso ao mundo não é ilusório nem indirecto, que o mundo que vê é o "mundo mesmo"18; mas sabe também que, se percebe algo, não é senão porque cada coisa está absolutamente junta a todas as outras, porque cada coisa é fio da filigrana do mesmo Ser, o que equivale, finalmente, a afirmar "que aquilo que é próprio do visível é ter uma dobragem de invisível (...) que ele torna presente como uma certa ausência." 19 O enigma da percepção encontra-se aí. E se ainda não o descobrimos, considera Merleau-Ponty, é por estarmos "de tal modo fascinados pela ideia clássica de adequação intelectual" - que se desprende da tese do nada prévio - que tal "pensamento mudo" da pintura foi muitas vezes recebido como "vão remoinho de significações" 20 e os seus

${ }^{14}$ BERGSON, H. L'évolution créatrice, cit. in. Le désir et la distance, p. 68.

15 Cf. MERLEAU-PONTY, M, Phénoménologie..., o. c., pp. 466-467:“" L'intérieur et l'extérieur sont inséparables. Le monde est tout au dedans et je suis tout hors de moi."

${ }^{16}$ Cf. MERLEAU-PONTY, M., "Le doute de Cézanne", in ID Sens et non sens, Nagel, Paris, 1966, p.26.

${ }^{17}$ MERLEAU-PONTY, M., L'oeil et l'esprit, Gallimard, Paris, 1964, pp. 81-82.

18 MERLEAU-PONTY, M., L' $x i l . . .$, o. c., p. 83.

${ }^{19}$ MERLEAU-PONTY, M., L'œil..., o. c., p. 85

${ }^{20}$ MERLEAU-PONTY, M., L'œil..., o. c., p. 91 
ensinamentos ignorados; ora, nessa ignorância agrava-se justamente a incompreensão do que realmente chama a pensar na questão da percepção: o modo como acedemos efectivamente ao mundo sem que isso seja a posição frontal de um sujeito ante um objecto integralmente disponível.

\section{2.}

Merleau-Ponty cedo compreendeu que, ao propor-se regressar à evidência da "estrutura do aparecer como tal" 21 , à "própria fenomenalidade dos fenómenos" 22 e, daí, até uma "descrição de essências" do vivido, a fenomenologia husserliana inflinge golpes certeiros na configuração ontológica que sustenta os grandes equívocos sobre a percepção - e que na via de uma superação necessária dos quadros teóricos que informam tal insustentável objectivismo fixista da adequação, fornecerá instrumentos precisos para recolocar a questão sobre novas bases. As potencialidades de tal empresa são imensas: se a fenomenologia é um estudo das essências, não deixa de ser também uma "filosofia que coloca essas essências na existência", não renegando a necessidade de meditar criticamente os nossos "vividos" e a facticidade do homem e do mundo; se é uma filosofia transcendental que suspende as afirmações da atitude natural, é também uma filosofia que, no regresso às coisas mesmas, "considera o mundo como já lá, antes da reflexão, como uma presença inalienável" 23 à qual uma consciência intencional permanece unida; se é uma tentativa de descrever a nossa experiência tal qual é, também se propõe como fenomenologia genética, capaz de interrogar a própria origem das formações de sentido transcendentalmente constituídas. Em tal horizonte de pensamento, interessará primeiro a Merleau-Ponty a possibilidade de retomar a questão da intencionalidade, ou seja, "do modo de abertura da consciência à realidade transcendente ${ }^{24}$, precisamente, a partir da questão da percepção. E esta, justamente, não parece desvendar-se como uma "ciência do mundo", mas como o fundo de todos os nossos actos que nos fazem participar no mundo. A percepção marca a especificidade de um "sujeito destinado ao mundo" 25 . E, neste sentido é, necessariamente, possibilidade de um "sujeito" corporeamente enraizado, de um sujeito que

${ }^{21}$ Le désir et la distance, p. 31.

${ }^{22}$ Le désir et la distance, p. 31. Mesma expressão em La perception, p. 43.

23 Cf. MERLEAU-PONTY, M., Phénoménologie..., o. c., p. I.

${ }^{24}$ Barbaras sublinha igualmente este aspecto (Cf. Vie et intentionnalité, p. 7), aludindo à definição husserliana de percepção em termos de "intuição doadora originária, fonte de direito para o conhecimento", segundo o célebre princípio de Ideen I, que obriga a ponderar o "substrato da intencionalidade" como o que nos dá as coisas em carne e osso.

${ }^{25}$ MERLEAU-PONTY, M., Phénoménologie..., o. c., p. V. 
apenas se sabe através do mundo e que, portanto, de certo modo, é ele próprio mundo - ou seja, de modo algum interioridade encerrada em si, mas essencial abertura e participação no mundo. A percepção é, neste sentido, o modo fundamental de ser de um sujeito cujo "interior" se encontra no (e através do) exterior do mundo e, por isso, de modo algum se pode entender como sede de qualquer verdade intrínseca. Percepcionar é, enfim, tentar ver como as coisas nos tocam ${ }^{26}$, é um ir concreto até às coisas que, simultaneamente, deixa ser as coisas no modo como convocam o olhar.

No Prólogo da Phénoménologie de la perception tais possibilidades de análise são desvendadas nas zonas de impensado do projecto husserliano, e através da tentativa de libertar as respectivas implicações mais radicais: se a "redução fenomenológica" é "regresso a uma consciência transcendental", ante cujo poder de constituição eidética o mundo "se desvelaria numa transparência absoluta" 27 , o seu maior ensinamento é, no entanto, "a impossibilidade da redução completa" 28 ; a atitude natural suspende-se para ser melhor compreendido o que ensina o contacto concreto com o mundo, mas, precisamente por isso, nunca deixa verdadeiramente de se insinuar no âmbito da consciência reduzida; as essências, se são o desejo legítimo de "recuar aquém do nosso comprometimento para o fazer aparecer ele próprio como espectáculo", não podem ser, então, o nosso objectivo último, já que o último verdadeiro, aquele para aquém do qual não podemos recuar e que se trata precisamente de tentar compreender não é senão, eis o decisivo, o próprio "comprometimento efectivo no mundo"; e se procurar "a essência do mundo não é procurar o que ele é em ideia, mas procurar o que ele é de facto para nós antes de qualquer tematização" 29 , ou seja, no seu próprio aparecer a uma consciência, então, esta é intencional num sentido preciso: se permanece ligada àquilo de que é consciência, é porque se encontra realmente comprometida no mundo para o qual não cessa de ser vocação, e do qual não deixa de acolher a constante e imperiosa solicitação ${ }^{30}$ - é, pois, intencional na exacta medida em que é perceptiva, perceptiva na exacta medida em que é corpo e corpo na exacta medida em que habita o mundo como justa contrapartida do modo como este nela se pronuncia infatigavelmente, inesgotavelmente. Neste sentido, a primeira tarefa de uma verdadeira filosofia da percepção deve ser a de denunciar a abstracção, o erro que consiste em supor qualquer tipo de totalização, ou qualquer tipo de posição

\footnotetext{
${ }^{26}$ Cf. MERLEAU-PONTY, M., "Le doute de Cézanne ", o. c., p. 33

27 MERLEAU-PONTY, M., Phénoménologie..., o. c., p. V.

28 MERLEAU-PONTY, M., Phénoménologie..., o. c., p. VIII.

${ }^{29}$ MERLEAU-PONTY, M., Phénoménologie..., o. c., p. X.

${ }^{30}$ MERLEAU-PONTY, M., Phénoménologie..., o. c, p. XIII.
} 
de sobrevoo que julgasse possível eliminar do mundo a sua "opacidade" e a sua "transcendência" 31 .

Husserl (como Barbaras notou com rara clareza ${ }^{32}$ ), já o havia intuido ao caracterizar a percepção como "doação por abschattungen" e ao reconhecer (tese denunciadora dos limites das concepções clássicas da percepção) que o esquisso é sempre uma esquiva. A presença perceptiva da coisa não equivale à sua posse integral; outrossim, a percepção apreende a própria coisa mas apenas porque esta não se apresenta totalmente. Não é um paradoxo: será que algo poderia ser dito percebido se a coisa não permanecesse como algo que transcende e se vem opor ao olhar? A ambivalência do percebido resume-se nesta enigmática esquiva pela qual um objecto se torna presente mas recua sempre sob a sua própria presença. Em Husserl, "longe de remeter apenas para a finitude das nossas faculdades, esta determinação terá um significado eidético"33 que vale para qualquer consciência pensável, já que define a ambivalência de que se nutre a realidade transcendente. E não sendo a consciência, por essência, senão aplicação ao mundo, senão de ponta a ponta ligação intencional àquilo de que é consciência ${ }^{34}$, a intencionalidade deve assentar necessariamente nesse movimento "pelo qual todo o esboço se ultrapassa em direcção a um objecto, que não sai no entanto da sombra e apela então, indefinidamente, novos esboços." ${ }^{35}$ Husserl viu, pois, com evidente acuidade que se na percepção a coisa é presente ela própria, isso não significa que ela esteja presente nela própria ${ }^{36}$. A percepção dá a coisa em carne e osso, mas não a dá adequadamente, exaustivamente; ela torna, então, claro que uma inadequação, uma não-coincidência, uma negatividade é inerente à doação do ente transcendente, que entre a coisa "enquanto ela própria" e a coisa "nela própria" resiste um distanciamento ${ }^{37}$ que alberga o mais essencial e enigmático da percepção. Mas será que Husserl leva, neste ponto, até ao fim a sua análise?

Se considerarmos uma vez mais a sua teoria da "doação por abschattungen" e seguirmos as análises de Barbaras, compreendemos bem o que está em questão: Husserl reconhece a distância que se cava entre a

${ }^{31}$ MERLEAU-PONTY, M., Phénoménologie..., o. c, p. VI

32 BARBARAS, R., Vie et intentionnalité. Recherches phénoménologiques, Vrin, Paris, 2003. p. 7. Citado Vie et intentionnalité. Idêntica formulação em La perception, p. 58

${ }^{33}$ Vie et intentionnalité, p. 7.

${ }^{34}$ La perception, p. 44

${ }^{35}$ Vie et intentionnalité, p. 7.

${ }^{36}$ Cf. La perception, p. 57. Veja-se ainda Vie et intentionnalité, p. 8, onde formulação semelhante é apresentada com as palavras de J. Patočka. Cf. PATOČKA, J., Papiers phénoménologiques, Millon, Grenoble, 1995, p. 123.

37 Vie et intentionnalité, p. 8. 
doação em carne e a doação adequada; indica, assim, a via do reconhecimento de uma negatividade essencial ao aparecer; mas, no final, pensa tal negatividade ainda sob a forma de um défice de presença, não se libertando do primado da adequação e não vendo que a époché permanece contraditória se apenas conduzir da suspensão do mundo à presença da coisa sustentada pela posição da consciência - e não for, justamente, o que nos conduz "de uma suspensão da coisa, através da negação do nada, ao reconhecimento do mundo" 38 , de um mundo que, assim reconhecido no resíduo de uma redução que nega o nada prévio, se desvendaria como “uma 'realidade' já lá, um fundo originário que, por essência, não pode ser negado porque é o solo prévio exigido por toda a negação." 39 E, assim sendo, a esquiva, o desajustamento constitutivo da percepção não pode ser uma deficiência mas sim uma condição de possibilidade.

Este ponto será, para Merleau-Ponty, igualmente decisivo: "regressar às próprias coisas, é regressar a esse mundo anterior ao conhecimento do qual o conhecimento fala sempre" 40 . A reflexão não pode pois almejar retirar-se do mundo para a unidade de uma consciência transcendental que seria o fundamento do mundo. Se fossemos um espírito desincarnado seguramente que o poderíamos fazer sem problemas; mas as nossas reflexões estão já sempre elas próprias emersas no que procuram captar. Se percebemos alguma coisa será, então, através dos fios que nos unem ao aparecer silencioso do mundo. Percebo como corpo situado dentro do mundo, preso à sua textura. $\mathrm{O}$ meu ponto de vista é de inerência e não de sobrevoo. E tal

${ }^{38}$ Le désir et la distance, p. 81.

${ }^{39}$ Le désir et la distance, p. 81. Para Barbaras, o rigor da époché só pode ser o de fixar a análise sobre "a estrutura do aparecer como tal" e, desse modo, destruir, a partir de um gesto de inflexível vigilância, todos os obstáculos que comprometem a apreensão do seu sentido verdadeiro. E porque esses obstáculos são aqueles que derivam da suspensão da existência do que aparece por relação ao nada, ou seja, de um gesto de determinação sob o modo do objecto, a époché deve desvendar-se, em derradeira análise, como negação do nada - único modo de combater o preconceito objectivista e aceder ao ser do que é. Barbaras compreende que o incumprido que resiste na teoria husserliana tem uma raiz que importa apontar: tal perspectiva teria permanecido presa de um plano originário ainda determinado pela presença do objecto, o que leva Husserl a caracterizar a esquiva inerente ao esboço como "inadequação"e "imperfeição"(La perception, p. 69. Le désir et la distance, p. 96), ou seja, no fundo, a recorrer a conceitos que traduzem uma ideia de défice, de falta, o que revela pressupor ainda na sua análise um horizonte de adequação. Dito de outro modo, segundo Barbaras, Husserl não pensa até ao fim o afastamento que descobre e enuncia porque, em nome do princípio de ausência de limites da razão objectiva, acaba por admitir a identidade entre o ser e a tese racional, que requer uma posse adequada. (Vie et intentionnalité, p.8).

${ }^{40}$ MERLEAU-PONTY, M., Phénoménologie..., o. c., p. III 
modo de pertença é uma tarefa sempre em aberto: para o corpo perceptivo não pode haver pensamento que abarque todo o pensamento ${ }^{41}$. E não será tal por, para esse sujeito corporeamente enraízado - como nota R. Barbaras - a estrutura do aparecer implicar que nada pode ser dado se o mundo, como solo dessa doação (como campo), não for ele próprio dado? Se a doação de uma coisa pressupõe a "doação originária do mundo", isso significa que aquilo que Husserl entende por "intuição doadora originária" deve conduzir a algo mais original ainda: à "doação do mundo como prévio e como condição de toda a aparição." 42 Mas, justamente, trata-se aqui de considerar uma estranha aparição: esse mundo não pode ser ele próprio dado, já que é uma totalidade omni-englobante, ou seja, pressupõe necessariamente que o sujeito perceptivo não o encontre totalmente. Não podendo ser evitado, o mundo, que é solo da percepção, igualmente não pode ser um dado porque em nenhum caso poderia a percepção enraizada no mundo coincidir com a plenitude do mundo e exaurir a sua opacidade. O que se passa é bem o inverso: o mundo deve, enquanto campo da aparição, sustentar "uma co-pertença, ela própria originária, do vazio e do cheio, da ausência e da presença"43 sem a qual nada apareceria.

Se na Phénoménologie Merleau-Ponty reconhece, de algum modo, a sombra de Husserl, apenas mais tarde, no entanto, ele próprio estará em condições de medir a que ponto deve chegar o aprofundamento desta possibilidade particular da fenomenologia. Recorde-se o momento em que o filósofo francês reconhece ter sido o primado da consciência e da relação sujeito/objecto a conduzir ainda a sua análise ao longo dos primeiros textos. Ao mesmo tempo que o assume, note-se, reconhece a necessidade de radicalizar a análise no sentido de uma investigação renovada do ser percebido que só o é porque permanece em cada presença ausente - "como presentificação de um impresentável", como horizonte ${ }^{44}$. Munido de um "método indirecto" que lhe comprova a necessidade de um nova reflexão ontológica ${ }^{45}$

${ }^{41}$ MERLEAU-PONTY, M., Phénoménologie..., o. c., pp. IX-X

${ }^{42}$ Le désir et la distance, p. 95.

${ }^{43}$ Le désir et la distance, p. 95-96

${ }^{44}$ MERLEAU-PONTY, M., Phénoménologie..., o. c., pp. 293. Le désir et la distance, p. 97.Com efeito, o "horizonte" nomeia esse enraizamento da aparição num invisível que ela apresenta na sua invisibilidade, esse excesso sobre si que é constitutivo da aparição enquanto ela é co-aparição do mundo, essa autonomia e distanciamento do aparecer face a todo o aparecente, essa distância na proximidade, essa profundidade cujo único modo de presença é o da não presentificação, o da esquiva, o da ausência.

${ }^{45}$ Cf. MERELEAU-PONTY, M., L'institution. La passivité. Notes de cours au Collège de France (1954-1955), Belin, 2003, p. 178: "Pourquoi l'ontologie phénoménologique est mal comprise? Que faire pour la développer ? Parce que nous sommes pris dans ontologie objectiviste et découvrons le perçu comme résidu." 
- capaz de dar conta de um mundo que é campo intensivo de encontros que flúem pela consciência perceptiva de modos que ela própria não consegue coordenar, capaz de confirmar que não possuímos acesso directo ao ser, que é indirectamente que nos relacionamos com ele, que as condições de inteligibilidade subsistem na filigrana do mundo - todo o esforço de Merleau-Ponty vai ser, precisamente, o de tentar libertar as implicações profundas de tal desajustamento.

Com razão situa Barbaras o contributo mais radical da Merleau-Ponty para a consideração da "inexaustividade da percepção" no conceito de "invisível." ${ }^{46}$ Pela nossa parte, diríamos, mais precisamente, que tal contributo se centra na própria tensão que Merleau-Ponty reconheceu, no interior do projecto fenomenológico que delineou em La phénoménologie de la perception, entre, por um lado, a ideia fenomenológica de uma consciência que é sempre consciência de alguma coisa e, por outro, o facto evidente de tal consciência ser intencional porque convocada, atravessada, descentrada, por aquilo de que é consciência. Pela orientação daquele primado da consciência, o percebido é directamente todo o ser percebido; pela evidência da insistente convocatória do mundo, torna-se claro que o ser percebido não só não se reduz ao "percebido" como é mesmo o facto de, em muito, o extravasar que parece permitir que algo se perceba. Merleau-Ponty viu bem esta tensão e a necessidade de radicalizar a análise no sentido de uma investigação renovada do ser percebido, que mostrasse ser a sua inadequação constitutiva a garantia da sua transcendência e o limite de qualquer manipulação de sobrevoo. Os resultados estabelecidos pelo seu "método indirecto" serão, neste sentido, decisivos: da análise da dimensão criativa da linguagem ${ }^{47}$, da meditação da pintura moderna, do estudo dos temas da "instituição", da "passividade"48 e da "natureza"49, recolhe Merleau-Ponty a indicação de uma ontologia por fazer; uma ontologia que se orienta para uma necessária noção de ser irredutível às capacidades perceptivas de discriminação do arranjo fenoménico do mundo. A ser assim, o ponto de apoio da consciência, tal como orienta ainda o percurso da Phénoménologie, deve efectivamente ser ultrapassado ou radicalizado, já que o índice último de uma consciência essencialmente incarnada e que se define por ser excesso em direcção ao mundo, depende,

46 Vie et intentionnalité, p. 9.

${ }^{47}$ Cf. MERLEAU-PONTY, M., La prose du monde, Gallimard, Paris, 1969. Recorde-se que este texto foi publicado postumamente, mas a sua redacção data dos anos de 1951-52.

48 Cf. MERLEAU-PONTY, M., L'institution. La passivité. Notes de cours au Collège de France (1954-1955), o.c.

${ }^{49}$ Cf. MERLEAU-PONTY, M., La Nature. Notes de cours du Collège de France, Seuil, Paris, 1994. 
justamente, do facto desse mundo permanecer o que a convoca; tal excesso é, pois, primeiro o do mundo por relação à consciência corporalizada. O que há que pensar é, então, a que ponto são as coisas que têm o nosso corpo perceptivo e não nós que temos as coisas ${ }^{50}$, a que ponto ser sensível se deve à sensibilidade inerente ao mundo que o faz corpo sensivel.

Não é por acaso que, na via de tal aprofundamento, sejamos conduzidos até Le visible et l'invisible, cujo primeiro capítulo é significativamente dedicado ao conceito de "fé perceptiva e sua obscuridade" 51 . Tal conceito mede a distância que Merleau-Ponty reconhecerá necessário afirmar por relação ao modo como pensou a percepção até aos anos quarenta. A fé perceptiva resume a ideia de que o mundo é o que aparece; mas igualmente indica que o que aparece estravaza em muito a capacidade perceptiva do corpo. Este é o meio que tenho de estar no mundo; mas enquanto está dentro desse mundo não pode deixar de também o esconder, já que o seu ponto de vista é, precisamente, de inerência. De onde uma conclusão decisiva: o mundo não é apenas o que eu percebo numa "proximidade absoluta", mas também o que se oferece como velamento numa "distância irremediável." 52 Ou seja, sublinhemo-lo, a essência da experiência perceptiva não pode mais ser entendida como correlação exaustiva ao ser percebido, uma vez que a abertura ao mundo não exclui, nem pode ignorar, um ocultamento possível. ${ }^{53}$ A percepção, então, deve ser entendida como o que nos faz "assistir a esse milagre de uma totalidade que ultrapassa o que julgamos ser as suas condições ou as suas partes (...) como se não existissem senão no seu seio e estivessem destinadas a perder-se nele" 54 . O próprio da percepção não é apresentar essa totalidade em si, mas assistir ao milagre dessa totalidade que permanece invisível em cada visível. De onde, mais do que "percepção" seja de uma "fé perceptiva" que aqui se trata: cruzamento ou identidade de uma credulidade e incredulidade originárias que tecem a nossa efectiva abertura a um mundo que, "mais do que afirmado e tomado na sua evidência, mais do que desvelado, é não dissimulado, não refutado" 55 .

Falar dessa invisibilidade constitutiva do visível equivale a dar um fundamento onto-fenomenológico à possibilidade de uma doação em carne e osso que não seja um puro dado exaustivo. Merleau-Ponty dá-nos os

${ }^{50}$ MERLEAU-PONTY, M., Le visible et l'invisible, Gallimard, Paris, 1964, p. 247:

"A savoir que les choses nos ont, et que ce n'est pas nous qui avons les choses."

${ }^{51}$ MERLEAU-PONTY, M., Le visible et l'invisible, o. c., p. 17 e ss.

52 MERLEAU-PONTY, M., Le visible et l'invisible, o. c., p. 23

${ }^{53}$ MERLEAU-PONTY, M., Le visible et l'invisible, o. c., p. 49

${ }^{54}$ MERLEAU-PONTY, M., Le visible et l'invisible, o. c., p. 23.

${ }^{55}$ MERLEAU-PONTY, M., Le visible et l'invisible, o. c., p. 49. 
instrumentos para pensar essa carne da doação como "o próprio invisível" 56 e, assim, concretiza uma via de superação da posição prejudicial do nada prévio. De facto, é libertados de tal escolho que podemos ponderar a dimensão de negatividade inerente ao Ser, dimensão que constitui o limite de qualquer objectivação: apreender a própria coisa não é nunca apreendê-la como objecto, mas segundo ela própria e "como a distância ou ausência que é", como profundidade, enfim, como radicalmente inadequada. Tal negatividade inerente ao Ser, escusado será repeti-lo, nada guarda de uma negatividade positiva prévia, contrária à positividade de um ser exaurível. O que Merleau-Ponty procura meditar é, ao invés, uma negatividade constitutiva, uma indeterminação originária, uma hesitação primitiva, um desajustamento interno - uma negatividade do positivo - inerente ao Ser.

Tal modo de assumir a negatividade inerente ao Ser, equivale a reconhecer que qualquer aparecer surge sempre sobre um fundo que, não sendo do nada, é necessariamente o de uma totalidade omni-englobante que compreende todo o aparecer possível, permanecendo, por definição, ela própria não totalizável ${ }^{57}$. O aparecer, enquanto tal, aparece sempre "no meio de outra coisa" e, por isso, precisamente, o englobante não aparece. Apenas assim se compreende a razão de nenhuma "coisa" nos aparecer, em verdade, rodeada de nada, mas sempre ligada aos seus arredores, sempre escorregando para todas as outras. Por isso é a percepção sempre relativa impercepção de um fundo irredutível; impercepção que não é devida a qualquer excesso de distância, ou a um em-si de positiva invisibilidade, mas a um excesso de proximidade que obriga a concluir estar em cada abertura ao mundo implicada a concomitante confirmação da pertença de cada coisa, e mesmo daquele que vê, a um mesmo "Ser polimórfico" e de "indivisão". Falamos de uma textura última que é a ordem da coexistência ou urdidura onde todas as coisas existem de perto "deslizando umas nas outras" 58 , que é "conjunto concreto de uma maneira de ser geral (...) que traz consigo um estilo de ser por todo o lado onde

56 Vie et intentionnalité, p. 9.

57 É neste sentido que, de acordo com Barbaras, a negação do nada nos conduz ao que, simultaneamente, é o mais evidente e o mais difícil de pensar: "que 'há' qualquer coisa" e que esse $i l-y$ - $a$ originário, condição de toda a aparição, tem por constituição o seu próprio aparecer com o qual, no entanto, porque intotalizável, nunca pode coincidir. O modelo da adequação deve, então, ser definitivamente subvertido, em nome do reconhecimento, em qualquer aparição, de um constitutivo - e fértil, na medida em que permite reconhecer, no escorregar de cada coisa, o todo do aparecer que a sustenta pela sua ocultação aparecente - desajustamento.

${ }^{58}$ MERLEAU-PONTY, M., Le visible et l'invisible, o. c., p. 272 
se encontra uma parcela" 59 , que é "unidade por transcendência". "Quando digo que o visível é invisível (...) - esclarece Merleau-Ponty a este propósito - quando digo que ver é ver mais do que aquilo que se vê, isso não deve ser compreendido como contradição, é a própria visibilidade que comporta uma não visibilidade" 60

Ora, é justamente a partir do sentido desse Ser vertical, selvagem, que Merleau-Ponty quer "restituir o mundo" 61 - um mundo que, justamente, "é constitutivo da aparição" no sentido em que "toda a aparição", fazendo-se no mundo, deve ser, por princípio, "co-aparição do mundo"62 - onde nada aparece fixo mas ligando-se a tudo o resto por via de uma membrana de invisibilidade que sustenta todo o visível. É esse mundo que nos tem, mais do que nós o temos a ele, que nos percebe mais do que nós o percebemos a ele. Mas, neste contexto, como se pode entender o sujeito que percebe? Como capacidade de desapossamento, como momento-lugar anónimo por onde pode passar a "relação a ele mesmo do visível" - que nesse "passar", precisamente, "me constitui como vidente, circulo que eu não faço mas me faz, enrolamento do visível sobre o visível." 63 A pergunta, no entanto, resiste: como qualificar positivamente o sentido de ser daquele que percebe? Não resistirá no projecto merleau-pontyano, a este respeito, igualmente uma zona de impensado, um espaço de incumprido?

${ }^{59}$ MERLEAU-PONTY, M., Le visible et l'invisible, o. c, 194.

${ }^{60}$ MERLEAU-PONTY, M., Le visible et l'invisible, o. c, p. 300

${ }^{61}$ MERLEAU-PONTY, M., Le visible et l'invisible, o. c., p. 306. Texto citado também por Barbaras em Vie et intentionnalité, p. 9.

${ }^{62}$ Le désir et la distance, p. 83. Também aqui devemos precaver-nos do modelo do objecto e do espírito da adequação: este mundo não é nunca objecto, mas "meio" (milieu); não o meio no qual se encontram objectos, mas milieu do aparecer. Melhor: o mundo não é estrutura prévia englobante à qual se viriam somar os aparecentes; é, antes, um momento do próprio aparecer. Aparecer, não é antes de mais aparecer a uma consciência, mas aparecer no seio do mundo. (Le désir et la distance, p. 83). E o mundo é, enquanto momento do aparecer, o a priori da pertença, do envolvimento, pelo qual o aparecer é sempre implicação de um fundo ou campo de aparição - campo que nenhum acto de nenhum sujeito poderia construir ou exaurir. Tais pressupostos são, para Barbaras, verdadeiros para todo o aparecer mesmo para o aparecer do homem a ele próprio. (Le désir et la distance, p. 83). Dito de outro modo, mesmo a aparição de mim a mim próprio implica a co-aparição originária do mundo. Há assim que considerar que há apenas um aparecer, seja qual for a natureza do que aparece. Ora, sendo que esse aparecer implica sempre inserção ou co-aparição no mundo, isso implica que algo do aparecer - digamo-lo assim, permaneça nesse modo da pertença.

${ }^{63}$ MERLEAU-PONTY, M., Le visible et l'invisible, o. c, p.185. 
4.

O mundo, cujo sentido se recupera a partir do Ser Vertical não é, na distância ou autonomia, uma qualquer esfera auto-suficiente e em si, uma "manifestação anónima" e absoluta. Ao contrário, como Merleau-Ponty ainda reconhece, tal fundo do mundo não dispensa a sua notável variante vidente-visível, tocante-tocada: o corpo que vê e sente. O corpo é bem um topos do enrolamento sobre si mesmo do Ser na via da sua expressão. Mas ao pensar esse corpo a partir de uma radical intra-mundaneidade e de uma clara viragem "anti-antripocêntrica" será que Merleau-Ponty fica em condições de dar conta da sua especificidade e das condições originárias que, do seu lado, tornam possível que algo se perceba?

Um impensado parece resistir no projecto merleau-pontyano ${ }^{64}$ : a consideração do corpo mergulhado no coração do mundo, preso antepredicativamente à teia de visibilidade e invisibilidade, e que percebe na exacta medida em que a deflagração do Ser o atravessa, não permite dar conta das condições de possibilidade originárias que, do lado daquele que percebe, continuam a ser requeridas para que algo chegue a perceber-se.

Eis o ponto que R. Barbaras viu com toda a acuidade. Porque, de facto, considera Barbaras, "se a essência do aparecer implica a aparição de um mundo, a essência desse mundo implica que ele não se pode distinguir da sua aparição"; e se ele não se pode separar da sua aparição, isso significa que o seu esse não se encontra desligado do seu percipi, o que, por seu turno, obriga a concluir, como viu J. Patočka, que "não pode ser pensado sem referência a um "quem" ao qual aparece"65. Este "quem" é seguramente corpo, porque o sujeito para o qual o mundo é deve fazer necessariamente parte da estrutura própria do aparecer. Não que constitua o mundo, o reduza a simples representação, ou o exaure; dizer que o mundo é para um sujeito equivale a afirmar que, concretamente, aquele para o qual há um mundo pertence também, ou é englobado pelo aparecer do mundo. O sujeito para o qual há um mundo deve fazer ele próprio parte do mundo - deve ser um sujeito incarnado ${ }^{66}$, e não, justamente, qualquer tipo consciência imanente e cristalina, constitutiva e de sobrevoo. Mas, qual o sentido de ser especificamente originário dessa incarnação? Qual o sentido de ser originário desse corpo? Será que o encontramos a partir da carne do mundo? Sem dúvida

64 Vie et intentionnalité, p. 13

${ }^{65}$ Le désir et la distance, p. 89. Cf. PATOČKA, J. Papiers phénoménologiques, o.c. p. 127.

${ }^{66}$ Le désir et la distance, p. 90. 
que, como mostrou Merleau-Ponty, ele deve procurar-se do lado do mundo do qual é uma parte. Mas, ainda assim, esse corpo não está no mundo à maneira de outros entes corporais; ele revela uma particularidade inelutável que é a de ser "variante mais notável" da carne do mundo. Ora, não será assim por, precisamente, ser a sua singularidade a de "perceber o aparecer"? A questão deve ser, pois, a de saber em que consiste e o que torna possível tal singularidade do modo de ser do $m e u^{67}$ corpo que percebe.

É no contexto da assim anunciada necessidade de remeditar a questão da percepção que têm vindo a suscitar crescente interesse as propostas saídas da pena de Renaud Barbaras. Julgamos justo o reconhecimento da importância de tal labor, não só por revelar uma consistente garra filosófica, mas também por nos propor uma via de análise de inequívoca feição original ao que, na via dos impensados que resistem nos grandes projectos de análise fenomenológica do tema da percepção, chama ainda a pensar.

Neste sentido, Le désir et la distance. Introduction à une phénoménologie de la perception (1999) - que retrospectivamente entendemos anunciar-se em La perception. Essai sur le sensible de 1993, e cujas repercussões são evidentes, por exemplo, nos artigos reunidos em Vie et intentionalité. Recherches phénoménologiques, publicação de 2003 - pode ser entendido como texto de charneira. A originalidade da reflexão que o nutre é indisputável. Seria um erro, pois, procurar nas investigações de Barbaras dedicadas à percepção apenas mais uma análise rigorosa do conhecedor de Husserl ou do famoso comentador de Merleau-Ponty. $\mathrm{O}$ rigor do comentador, a minúcia do leitor competente, as opiniões do intérprete estão, certamente, presentes nos textos indicados: mas estão-no ao serviço de um proposta filosófica nova que merece ela própria, de pleno direito, o comentário. Tanto mais quanto nos instiga a regressar a uma necessária descrição sem pressupostos da percepção mesma - a uma descrição que não receie o campo da crítica às categorias que lhe foram sendo apensas erroneamente e que mais não fizeram do que esvaziá-la da sua realidade, e que não tem pejo em realçar ou actualizar os contributos que desbravaram já algum do caminho a percorrer.

Ensaiemos ponderar a novidade da meditação de Barbaras, tal como se estrutura ao longo de alguns pontos axiais: a afirmação da natureza intra-

${ }^{67} \mathrm{Cf}$. Vie et intentionnalité, p. 15 : “ C'est pourquoi, si l'existence doit bien être référée à la corporéité, celle-ci doit elle-même être saisie au plan existentiel: c'est à cette condition seulement que l'on pourra, en retour, accéder au sens d'être véritable du corps tel qu'il est annoncé, sans pouvoir être thématisé, para Merleau-Ponty." 
mundana do sujeito do aparecer; o reconhecimento da sua dimensão de negatividade constitutiva da presença em horizonte; a ligação de tal negatividade a um movimento originário que obriga a ponderar o carácter transcendental do movimento vivo; a ligação do movimento à percepção; o esclarecimento do modo de ser essencial da percepção em termos de desejo.

Para começar, considera Barbaras, há que indagar sobre o sentido exacto que se pode atribuir à ideia de que não há aparecer que não seja aparecer para alguém. E, neste sentido, não pode obliterar-se a questão de saber qual é o modo de ser originário daquele para o qual há mundo. Ora, pelo que já vimos, torna-se necessário concluir que esse modo de ser deve ter como traço originário a aptidão para acolher um mundo que se dá como não-totalizável, ou seja, como estrutura de horizonte. O horizonte dá-se, para lá da oposição do positivo e do negativo, como "um certo não-ser", como a presença específica que convém à ausência irredutível do mundo"; a subjectividade que interrogamos, só pode ser, pois, aquela para a qual há um aparecer sempre inadequado, ou seja, o que é necessariamente o mesmo, aquela que se encontra situada dentro do mundo e acompanha como significativa a sua presença irrepresentável.

Apenas para um "sujeito" que não sobrevoa o mundo mas lhe pertence (subjectividade incarnada, ou melhor, que não pode ser senão a sua incarnação), de facto, o aparecer do mundo é o de uma globalidade intotalizável, o de um certo estilo de ser espalhado por todo o lado onde se encontra uma parcela, o de uma presença que se acolhe como ausência mais do que se concebe, à qual se adere mais do que se tenta totalizar. É forçoso, no entanto, que não nos detenhamos nesta ideia de incarnação e procuremos mais fundo o seu traço originário, a sua derradeira condição de possibilidade. Há que dar conta do modo como originariamente alguém pode perceber alguma coisa em e através de uma aparição do mundo que é sempre recuo, ausência, invisibilidade.

Tal possibilidade, como já ficou claro, não podendo ser a de uma capacidade subsuntiva de adequação integral, mas apenas a de um sujeito "incarnado", logo, intra-mundano, obriga a reconhecer que aquele para o qual há mundo é, necessariamente, "um momento do aparecer"68. Há, pois, que assumir essa "situação inédita de uma condição que não pode ser condicionante senão estando situada do lado daquilo de que é condição, de um transcendental que está, por assim dizer, atrasado em relação a si próprio" ${ }^{69}$, de modo que é necessariamente envolvido pelo que condiciona, embargado pela empiricidade que polariza, sustentado pela presença

${ }^{68}$ Recorde-se Le désir et la distance, p. 91

${ }^{69}$ Le désir et la distance, p. 104. 
cruzada de ausência que faz convergir. Assim entendida a questão, é a própria ideia de subjectividade que exige ser redefinida, justamente a partir dessa essencial constituição - corpórea, vital - adaptativa à estrutura da presentificação em ausência do mundo, redobradora da esquiva em cada presença, da sombra em cada coisa, da relativa impercepção em cada percepção. Na raiz da minha incarnação, em suma, deve indagar-se essa enigmática aptidão para entrar no mundo como impresentável, para fazer convergir o que recua, para acompanhar a ausência que descentra cada presença, para aspirar ao excesso que subverte silenciosamente cada certeza - capacidade que será, então, a de testemunhar por dentro a co-pertença do vazio e do cheio, da ausência e da presença, do pleno e do esgueire, do positivo e do negativo. Segue-se daqui que tal sujeito deve comportar necessariamente ele próprio uma dimensão de negatividade" "70; impossível, de facto, a um sujeito que estivesse no mundo à maneira dos objectos, repousando sobre si mesmo, ser essa abertura polarizadora do mundo. Outrossim, deve ser originariamente constituído pela possibilidade do seu próprio excesso, da sua própria negação, ou seja, ser essencial imcompletude, ou constitutiva abertura ao mundo; o mesmo é dizer que o caracteriza o facto de no mundo apenas - e na negatividade que lhe é inerente - encontrar a via de acesso à sua própria identidade sempre por fazer, ao seu aparecer a si próprio sempre provisório.

Mas onde radica essa insólita constituição de um "sujeito" sempre além ou aquém de si próprio? A sua medida (incomensurável) encontra-se no movimento. Mover-se é, de facto, não repousar em si próprio, realizar-se no diferente não exaurível, estar sempre para além ou para aquém de si próprio. Neste sentido, representa - enquanto "élan dinâmico" que faz da existência, constitutivamente, ex-istência, ida para fora de si, excesso em direcção às coisas e, ao mesmo tempo, recomeço incessante e incompletude - uma forma de negatividade interior ao mundo (não-coincidência, desproporção, "negatividade natural" 71 e "concreta da vida"72), mas uma negatividade que, longe de o comprometer, parece particularmente apta a redobrar e a ser redobrada por uma presença que apenas se manifesta retirando-se sob a aparição. O movimento é, de facto, a medida de um eu posso não impositivo, de uma actividade que não é contrária à passividade; e, neste sentido, é justa capacidade de correspondência por aproximação a uma realidade cuja visibilidade é transida de uma invisibilidade sustentadora. Como defende Barbaras, se o mundo é o que "se excede incessantemente (...) o que permanece sempre aquém das suas aparições finitas", só o

\footnotetext{
${ }^{70}$ Le désir et la distance, p. 108.

71 Vie et intentionnalité, p. 18.

${ }^{72}$ Le désir et la distance, p. 109
} 
movimento que é abertura inesgotável "pode visar a impresentabilidade ou a diferença pura do mundo"73, só o movimento pode seguir as indicações de um aparecer "sobre-objectivo"74.

O movimento de que falamos é efectiva "penetração" na concretude do mundo, sem ser expressão exterior de qualquer egoidade inclusa. A sua subjectividade não é comprometida ou degradada na exteriorioridade; a invasão do mundo é, antes, a sua condição, na medida em que "qualquer exteriorização do sujeito no movimento" tem por "contrapartida o refluxo do movimento para uma forma de interioridade" 75 . Mas esta interioridade, eis o decisivo, não é senão o topos de uma incompletude que é mantida e sustentada pela ausência do mundo em cada aparecer. Por isso, em cada uma das suas realizações, o movimento não se esgota mas reactiva incessantemente. Ele é "ao mesmo tempo penetração na exterioridade e poder de renovação indefinida" 76 . E, neste sentido, precisamente, respeita as exigências da transcendência perceptiva: atinge a própria coisa, mas apenas enquanto ela, fazendo jogar o invisível, a ausência, o esgueire, suscita um novo movimento.

Nesta via de aprofundamento necessário, é nas reflexões radicais de J. Patočka sobre o movimento - inigualáveis na posteridade de Husserl que Barbaras encontra as indicações mais férteis, nomeadamente, no reconhecimento de que o "estatuto ontológico de base de toda a existência"77 é a corporeidade, de que o ser do fenómeno é movimento, e de que sujeito para qual há fenómenos é um eu posso - ou seja, uma subjectividade que é, precisamente, unidade de corporeidade e movimento. As linhas mais provocadoras do projecto de Patočka de uma fenomenologia assubjectiva ${ }^{78}$, longe de descartarem uma interrogação renovada sobre o sentido de ser

73 Vie et intentionnalité, p. 19.

74 Vie et intentionnalité, p. 21. Apenas um movimento que é, logo à partida, descentramento do sujeito em relação a si próprio - porque encerra "uma ambivalência interna" que parece constantemente procurar cindi-lo -, pode ser a base de um saber do mundo já que, longe de comprometer ou violentar o mundo num desejo de totalização, é aquele que põe a subjectividade do lado das coisas sem a comprometer, fazendo dela iminente capacidade de seguir as indicações veladas do aparecer e da sua teia de invisibilidade.

${ }^{75}$ Le désir et la distance, p. 116

${ }^{76}$ Le désir et la distance, p. 118

${ }^{77} \mathrm{Cf}$. Vie et intentionnalité, p. 16.

${ }^{78}$ Cf. PATOČKA, J., Papiers phénoménologique, o. c., p. 127. Cf. ID, Qu'est-ce que la phénoménologie, Millon, Grenoble, 2002, 165 e ss. Cf. PATOČKA, J., Le monde naturel et le mouvement de l'existence humaine, Kluwer, 1983, p. 96. Mesma passagem escolhida em Vie et intentionnalité, p. 16. Nesse contexto, Patočka afirmará que ter um corpo é a nossa possibilidade primeira, base ontológica da qual dispomos e à qual pertencemos mas 
do sujeito para o qual há mundo, assumem a necessidade de sua remeditação à luz de uma efectiva "fenomenologia e metafísica do movimento", assim configurando um ambicioso regresso a Aristóteles que Barbaras, por seu turno, também não regateia ${ }^{79}$. A este último interessa, nas propostas do fenomenólogo checo, o facto de não conduzirem a qualquer concepção de um corpo em termos de presença subsistente à qual se juntaria a faculdade ou propriedade de se mover", mas de, ao invés, demonstrarem que o movimento é efectivamente a essência da incarnação ${ }^{80}$. Tal tese permite finalmente compreender que não é em derradeira análise por sermos incarnados que algo pode ser percebido por nós; é por sermos corpo de movimento, é por existirmos sob o modo da relação, da abertura e da incompletude que podemos ser corpo para o qual há mundo como horizonte.

Mas, não esqueçamos, tal modo de ser subjectivo é sustentado pelo próprio mundo. Este, enquanto horizonte ou modo constitutivo do aparecer, é realmente o a priori da aparição do sujeito a si próprio. Há, pois, que pensar a aparição de tal "subjectivo" no aparecer do mundo, ou seja, como seu momento. E isto, como indicou Patočka, não mais pode ser feito com recurso a qualquer representação interior, a qualquer abstracção de uma consciência repleta de vividos. Momento do aparecer, acedendo a si através do mundo, radical a incompletude, o modo de ser essencial do subjectivo descobre-se na assunção de uma corporeidade viva e activa ${ }^{81}$. Ou seja, um tal sujeito que é "momento do aparecer" e, nesse sentido, "mediador do aparecer", não pode ser senão um sujeito vivo, corporalizado, sensível e motor, ao mesmo tempo preso no mundo e livre. Merleau-Ponty, segundo Barbaras, teve, a este respeito uma intuição decisiva numa das suas aulas no Collège de France dedicadas à ideia de Natureza quando sustentou: não se pode 'introduzir um 'perceber' sem 'ligações corporais'. Não há percepção sem movimentos prospectivos, e a consciência de se mover não é pensamento de uma mudança de lugar objectiva, não nos movemos como uma coisa, mas por redução de afastamento e a percepção não é senão o outro pólo desse afastamento,

não escolhemos; a tal "posse" corresponde a capacidade de o mover, ou seja, é o movimento a determinação existencial mais originária da nossa corporeidade; e juntos fazem a essência da subjectividade.

79 Le désir et la distance, p. 109: "On le voit, nous nous inscrivons ici dans une perspective résolument aristotélicienne."

80 Cf. Vie et intentionnalité, p. 17.

${ }^{81}$ Vie et intentionnalité, p. 17. Cf. BARBARAS, R. "A Fenomenologia de J. Patočka" in Phainomenon, 11 (2005), pp. 77-99. 
afastamento mantido." 82 Segundo Barbaras, Merleau-Ponty nunca foi tão longe no que concerne a questão da percepção: reconhece a inscrição corporal do aparecer; acrescenta que a intramundaneidade de tal sujeito perceptivo consiste num "movimento prospectivo", que de nenhum modo se pode confundir com a mera deslocação objectiva ${ }^{83}$; e com a noção de écart reconhece que tal sujeito perceptivo não é o sujeito de um movimento, mas identidade com a tensão própria do movimento - identidade com um excesso que reduz o afastamento em relação ao que o pode completar (a transcendência do mundo englobante), mas que sendo intramundano, aproxima-se mantendo o afastamento do mundo; identidade, enfim, ao excesso que "interroga e suscita pelo interior a aparição do mundo" 84 na sua radical inadequação.

Neste sentido, Merleau-Ponty parece orientar-nos para a consideração de que a estrutura de horizonte do aparecer e a inscrição da percepção num movimento "são duas faces de uma mesma situação", sendo que nessa unidade relacional "o excesso não positivo do horizonte sobre toda a aparição responde à diferença inassinalável do poder sobre o fazer"85: o horizonte da aparição vem encher o afastamento que o movimento interroga como carência, falta ou ausência; mas, simultaneamente, não deixa de ser o que continua a cavar distâncias como radical impresentabilidade, assim fazendo com que "cada percepção finita reclame outros movimentos prospectivos" 86 . No excesso do eu posso sobre o eu faço, se compreenderá, pois, que a intencionalidade perceptiva depende necessariamente de uma vocação do movimento para um todo que nunca se dá totalmente e, por isso, como já referimos, o reactiva incessantemente. Eis o sentido derradeiro a atribuir à evidência sempre esquecida de que "o perceber, enquanto advém do meio do mundo, enquanto é incarnado, é um mover-se"87.

Ora, se o movimento é condição de fundo da intencionalidade preceptiva (movimento e percepção identificam-se) não se deverá, então, concluir que esta implica e é implicada desde sempre pelo "círculo da vida"? A meditação de Barbaras segue os caminhos de uma resposta

82 MERLEAU-PONTY, La Nature, o. c., p. 273. Barbaras cita esta passagem em Le désir et la distance, p. 119.

${ }^{83} \mathrm{Cf}$. Le désir et la distance, p. 120.

${ }^{84}$ GODDARD, J. Ch., Violence et subjectivité, Vrin, Paris, 208 p. 130.

${ }^{85}$ Le désir et la distance, p. 119.

${ }^{86}$ Le désir et la distance, p. 120: "Le mouvement est tentative de réduction d'un écart mais, en vertu de sa tension fondamentale, de l'excès constitutif du pouvoir sur le faire, l'écart se trouve maintenu et c'est pourquoi le mouvement donne lieu à une perception: la perception appara"t donc comme l'envers de l'inaccomplissement du mouvement."

87 Vie et intentionnalité, p. 17-18. 
afirmativa a tal questão: há que "caracterizar a intencionalidade enquanto precisamente atravessada pela deiscência da existência e da vida, de referir pois o movimento à sua fonte mais profunda que dá conta desse redobramento interno, pelo qual ele não é excesso para o mundo senão em excedendo-se enquanto movimento puramente vivo" 88 , enquanto desmesura de toda a posição finita ${ }^{89}$. Dito de outro modo: a reinterpretação da percepção segue lado a lado com a redefinição do movimento, ou melhor, "não há determinação autêntica da percepção senão como caracterização do movimento vivo." 90

Sublinhe-se a originalidade da senda que assim se desbrava: uma investigação transcendental que, como tal, interrogue o sentido de ser e a validade do mundo sem o reduzir à objectividade, não pode dispensar-se de indagar sobre o modo como esse mundo chega a encontrar-se polarizado por uma subjectividade intra-mundana (cuja característica mais singular é a de ser constituída por uma negatividade em relação ao aparecer de horizonte); e se tal investigação continuar sem reduzir o mundo a qualquer adequação subjectivista, não deixará de ponderar a que ponto tal subjectividade se define (ou redefine) a partir do movimento, logo, a partir da vida do vivente que é relação a um todo. Nela há, então, que reconhecer um valor transcendental. A divisão entre ser vivo e ser humano, vida e existência deve ser superada: o modo de ser humano deve esclarecer-se a partir do modo de ser vivo, o modo de ser da existência a partir do modo de ser da vida ${ }^{91}$ - como já haviam sugerido as indicações de Goldstein ${ }^{92}$ (que, mais do que as análises da animalidade proposta por Heidegger ${ }^{93}$, subvertem as separações entre "somático e psíquico" e os descobrem "expressões da totalidade orgânica, isto é, modalidades do ser em vida"), ou as propostas de Von Weisäcker (que radicalizam as possibilidades de meditar a ligação entre percepção e movimento como dois aspectos, "indissoluvelmente ligados, de relação ao meio"94).

A percepção redefinida a partir do movimento prospectivo do vivente não pode ser produtora da aparição. O seu papel será polarizador ou actualizador do aparecer. Bergson viu-o antes de todos os outros. Segundo o célebre primeiro capítulo de Matière et mémoire, percepcionar é limitar, enquadrar o que aparece a partir do fundo da totalidade das imagens ${ }^{95}$.

\footnotetext{
${ }^{88}$ Vie et intentionnalité, p. 21.

${ }^{89}$ Le désir et la distance, p. 118.

${ }^{90}$ Le désir et la distance, p. 120

${ }^{91}$ Cf. GODDARD, J. Ch., Violence et subjectivité, o. c., p. 130.

${ }^{92}$ Le désir et la distance, p. 110 e ss ; 142 e ss.

93 Cf. Vie et intentionnalité, p. 197.

${ }^{94}$ Le désir et la distance, p. 112.

95 Le désir et la distance, p. 121; 150 Cf. o primeiro capítulo de BERGSON, H., Matière et mémoire, Édition du Centenaire, P.U.F., Paris, 201, pp. 167-223.
} 
A percepção consciente surge, assim, no momento em que o corpo opera, sobre o fundo das imagens que é a matéria universal, uma selecção funcional e pragmática. Neste sentido, a percepção não é entendida como qualquer gesto de uma espiritualidade interna; outrossim, resulta da relação de cada corpo vivo ao todo do universo. E tudo muda com essa presença activa do corpo: ele faz bascular, curvar, convergir o universo à sua volta." 96 O corpo vivo "anexa o mundo à sua acção"97. E, neste sentido, justamente, segundo Bergson, a consciência não mais pode ser entendida como dizendo respeito apenas ao humano, mas ao vivente. A percepção, sendo um agir mais do que um contemplar, compreende-se (porque se dobra de movimento) a partir da vida. Mas que a consciência - e com ela a percepção - se desvende assim a partir da vida, não implica que a sua explicação dependa de uma qualquer opção biologista que encontraria no cérebro as respostas últimas; o cérebro tem, certamente, um papel, mas não deve ser sobrevalorizado: não é o cérebro que produz o processo de consciencialização; "é a relação corpo vivo e universo que a engendra." 98 Insólito resultado: o bergsonismo que passa amiúde por ser um espiritualismo dogmático é, no fundo, uma filosofia que "mergulha a consciência num universo material" 99 e estabelece a tese de que há um plano comum à natureza e à consciência viva (com diferentes durées).

Tais indicações confirmam o caminho que, para Barbaras é o correcto. A Bergson não terá faltado senão ponderar plenamente que "se a percepção de um objecto se precede dentro da totalidade das imagens, o sujeito dessa percepção deve igualmente preceder-se sob a forma de um sujeito para essa totalidade." ${ }^{100} \mathrm{O}$ ponto cego da doutrina bergsoniana é, pois, a consideração plena do sujeito do aparecer - desse sujeito da percepção como vivente e do traço originário do seu modo de ser para uma totalidade não-totalizável.

Se, no entanto, seguirmos a tradição dominante de uma filosofia da vida que se procura constituir a partir da análise estrita do ser vivo - ou seja, que se centra sobre a análise do dinamismo vital e entendendo-o como processo de auto-conservação traduzível numa "pulsão", tensão essa que, por seu turno, é entendida como dirigida a um objecto desinibidor, ou seja, a uma necessidade - falharemos o essencial. Seguindo tal perspectiva, de facto, não

95 Le désir et la distance, p. 121; 150 Cf. o primeiro capítulo de BERGSON, H., Matière et Mémoire, Édition. du Centenaire, P.U.F., Paris, 201, pp. 167-223.

96 Cf. BERGSON, H., Matière et mémoire, o. c., p. 170-172.

${ }^{97}$ MONTEBELLO, P., Nature et subjectivité, Million, Grenoble, 2007, p. 80.

98 MONTEBELlO, P., Nature et subjectivité, o. c., p. 81. Cf. Le désir et la distance, p. 150 e ss. Cf. BERGSON, H., Matière et mémoire, o. c., p. 190.

99 MONTEBELlO, P., Nature et subjectivité, o. c., p. 81. Cf. BERGSON, H., Matière et Mémoire, o. c., p. 190.

${ }^{100}$ Le désir et la distance, p. 126 
podemos ver nos movimentos senão a expressão de faltas circunscritas ${ }^{101}$. Se interrogarmos, no entanto, o "autêntico valor transcendental"102 que descortinámos, através do movimento, na vida do vivente verificamos que o seu traço originário é aspiração inesgotável. O sujeito do movimento não se esgota na apropriação de qualquer coisa; ao contrário, descobrimos que é no excesso, na desmesura, na não-coincidência, na relação ao mundo, que $o$ sujeito se constitui. Ensaiemos, pois, uma outra orientação: a de uma filosofia não biologista da vida que procure compreender o ser vivo a partir da vida. Tal perspectiva não pode deixar de reconhecer o dinamismo vital como movimento da vocação de ausência em cada presença; e, do mesmo modo não ignorará que a "pulsão" é impulsividade e negatividade no coração da vida. E na via desta perspectiva - que é a de R. Barbaras - compreenderemos, finalmente, que o essencial do movimento vivo só pode ser desejo ${ }^{103}$.

O desejo tem como característica distintiva o facto de o objecto que o satisfaz "o intensificar na exacta medida em que o satisfaz. A satisfação significa a recondução do desejo, mais do que a sua abolição" 104 . O desejo, tal como Barbaras o assume, não é o contrário de uma ausência, não se reduz a uma carência que conduza, por exemplo, a satisfação das necessidades vitais; mas também não é um qualquer estado de plenitude fechada em si própria. Ele é, outrossim, puro transbordar que nada pode vir preencher que nenhum objecto pode apaziguar. Neste sentido, o desejo liga-se a uma ausência, a uma negatividade essencial e inesgotável que o sustenta e através do qual se reactiva; o que o satisfaz é, pois, o que em cada satisfação permanece em recuo e, assim, o renova como constitutivo excesso. O que permanece velado em cada satisfação não é, então, um defeito ou carência, mas o efectivamente visado pelo desejo ${ }^{105}$. Assim, conclui Barbaras, o desejo coloca-nos em contacto com algo que não é um objecto ${ }^{106}$; quando muito, liga-nos à ausência que se dá como o que falta em cada objecto, como o que parece conduzir, em vazio, o aparecer de um objecto. Ora, é

101 Vie et intentionnalité, p. 21-22.

102 GODDARD, J.Ch., Violence et subjectivité, o. c., p. 131.

103 Le désir et la distance, p. 136. Cf. para a questão da «pulsão», Vie et intentionnalité, p. 185 e ss. Continuamos a seguir a análise de GODDARD, J.Ch., Violence et subjectivité, o. c., p. 128.

104 Le désir et la distance, p. 136

105 Cf. Le désir et la distance, p. 137. Barbaras recorre aqui, para depois, a ultrapassar às intuições de Husserl no momento em que passa a uma perspectiva "genética".

106 Le désir et la distance, p. 138: «On a ici un rapport à quelque chose qui ne peut pas être un objet et même si le désir concerne un objet, ce qu'il vise spécifiquement est d'un autre ordre.» 
justamente um laço deste tipo que deve caracterizar o sujeito de um aparecer de horizonte.

O fio de sentido que une corpo vivo, subjectividade e mundo, ilumina-se no desejo. Barbaras esclarece, deste modo, "que apenas um sujeito vivo em movimento e desejante introduz uma dimensão de negatividade suficiente para dar conta da relação entre a posição de um aparecer impresentável e invisível e a sua aparição subjectiva" 107 . E esse é bem o núcleo do problema da percepção: o modo como se conciliam, como se misturam e parecem nascer um do outro, um sujeito perceptivo que percebe o mundo para si como prova de um conteúdo imanente e um mundo como exterioridade, ou ser à distância.

"O desejo - sustentará, de modo inequívoco, R. Barbaras - qualifica o sentido originário do sujeito e, enquanto existencial (deveria dizer-se Vital) da percepção" constitui a resposta à questão sobre o sujeito do aparecer ${ }^{108}$. O desejo é movimento, portanto vida; é a justa negatividade que co-responde às indicações da co-aparição invisível do mundo; mas, reversivelmente, se não há desejo senão como vida é porque "não há ser constituído do mundo senão como omni-englobante e, portanto, ao mesmo tempo não constituível" 109 . No desejo, identificam-se a actividade da não-coincidência e a passividade que é a justa resposta à transcendência intotalizável do mundo. Em suma, o desejo dá conta dos traços fundamentais da percepção; ou talvez seja a própria intencionalidade perceptiva que, justamente, se pode redefinir ela própria a partir do desejo - a partir da vida, como abertura, aspiração, incompletude, inadequação que apenas do lado do inesgotável do mundo se reconquista como tal. Neste sentido, o desejo é a condição de possibilidade por detrás da percepção, mas num sentido preciso: no sentido em que Merleau-Ponty afirmava que "a aparição do mundo para o corpo é ao mesmo tempo aparição do mundo pelo corpo e no meio do corpo"110. Por isso pode Barbaras concluir: porque o vivente não existe senão permanecendo aquém do seu ser, ele não exibe a totalidade senão sob a forma do que a nega e não contém, pois, o mundo senão como o que o contém: o desejo é facto do transcendental, ou o transcendental como Facto, a forma concreta do seu atraso originário." 111 A atenção ao vivente a partir da vida (e a partir de um viver que ultrapassa o Erleben, que é mais primitivo do que a distinção entre vivido e viver) tem aqui o seu corolário: o desejo

107 MONTEBELLO, P., Nature et subjectivité, o. c., p. 77

${ }^{108}$ Le désir et la distance, p. 142.

${ }^{109}$ Le désir et la distance, p. 153.

110 Cf. Le désir et la distance, pp. 104 n.; 148. Cf. MONTEBELLO, P., Nature et subjectivité, o. c., p. 77

111 Le désir et la distance, p. 153. 
é o tecido do quiasma com o qual Merleau-Ponty definia, em derradeira análise, a fenomenalidade ${ }^{112}$. $\mathrm{O}$ desejo é o sentido derradeiro da carne.

\section{REFERÊNCIAS BIBLIOGRÁFICAS}

BARBARAS, R., La perception. Essai sur le sensible, Hatier, Paris, 1994. Vrin, Paris, 2009.

BARBARAS, R., Le désir et la distance. Introduction à une phénoménologie de la perception, Vrin, Paris, 1999.

BARBARAS, R., Vie et intentionnalité. Recherches phénoménologiques, Vrin, Paris, 2003.

BARBARAS, R., “A Fenomenologia de J. Patocka” in Phainomenone, 11 (2005).

DIAS, Isabel, Matos, Uma Ontologia do Sensível. A Aventura Filosófica de Merleau-Ponty, Centro de Filosofia da Universidade de Lisboa, Lisboa, 1999.

GODDARD, J. Ch., Violence et subjectivité, Vrin, Paris, 2008.

MERLEAU-PONTY, M., Le primat de la perception et ses conséquences philosophiques, Verdier, 1996.

MERLEAU-PONTY, M., "Le doute de Cézanne”, in ID Sens et non sens, Nagel, Paris, 1966.

MERLEAU-PONTY, M., La structure $d u$ comportement, (1942), P.U.F., Quadrige, Paris, 1990.

MERLEAU-PONTY, M., Phénoménologie de la perception, Gallimard, Paris, 1945.

MERLEAU-PONTY, M., La prose du monde, Gallimard, Paris, 1969.

MERLEAU-PONTY, M., L'institution. La passivité. Notes de cours au Collège de France (1954-1955), Belin, 2003.

MERLEAU-PONTY, M., La Nature. Notes de cours du Collège de France, Seuil, Paris, 1994.

MERLEAU-PONTY, M., Le visible et l'invisible, Gallimard, Paris, 1964.

MERLEAU-PONTY, M., L'oeil et l'esprit, Gallimard, Paris, 1964.

MONTEBELLO, P., Nature et subjectivité, Million, Grenoble, 2007.

PATOCKA, J., Le monde naturel et le mouvement de l'existence humaine, Kluwer, 1983.

PATOČKA, J., Papiers phénoménologiques, Millon, Grenoble, 1995.

112 Le désir et la distance, p. 153. 